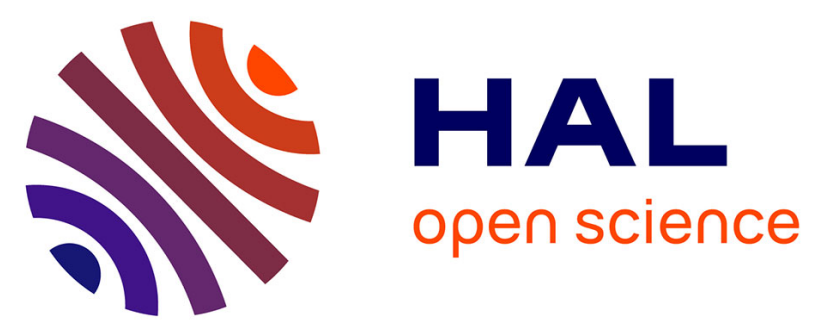

\title{
Diastereoselective supramolecular ion-pairing between the TRISPHAT anion and pro-chiral heptamethine cyanine dyes
}

Pierre-Antoine Bouit, Christophe Aronica, Laure Guy, Alexandre Martinez, Chantal Andraud, Olivier Maury

\section{To cite this version:}

Pierre-Antoine Bouit, Christophe Aronica, Laure Guy, Alexandre Martinez, Chantal Andraud, et al.. Diastereoselective supramolecular ion-pairing between the TRISPHAT anion and pro-chiral heptamethine cyanine dyes. Organic \& Biomolecular Chemistry, 2009, 7 (15), pp.3086-3090. 10.1039/B905366B . hal-01320587

\section{HAL Id: hal-01320587 \\ https://hal.science/hal-01320587}

Submitted on 26 Nov 2019

HAL is a multi-disciplinary open access archive for the deposit and dissemination of scientific research documents, whether they are published or not. The documents may come from teaching and research institutions in France or abroad, or from public or private research centers.
L'archive ouverte pluridisciplinaire HAL, est destinée au dépôt et à la diffusion de documents scientifiques de niveau recherche, publiés ou non, émanant des établissements d'enseignement et de recherche français ou étrangers, des laboratoires publics ou privés. 


\title{
Diastereoselective supramolecular ion-pairing between TRISPHAT anion and pro-chiral heptamethine cyanine dye.
}

\author{
Pierre-Antoine Bouit, Christophe Aronica, Laure Guy, Alexandre Martinez, Chantal Andraud, Olivier \\ ${ }_{5}$ Maury*
}

The supramolecular interactions between enantiopure TRISPHAT anion

10 (tris(tetrachlorobenzenediolato)phosphate) and various non chiral or pro-chiral heptamethine cyanine cations have been studied in the solid state by X-rays diffraction and in solution by NMR spectroscopy. The presence of the conformationnally restricted ter-butyl functionnalized

cyclohexenyl moieties is responsible for the asymmetric shape interaction between the two ions revealing the chirality of the molecule. On the other hand, the strength of this interaction is

15 controlled by the nature of the distal substituents.

\section{Introduction}

Since its discovery in 1997 by Lacour and co-workers ${ }^{1}$ and its 20 large scale resolution, ${ }^{2}$ enantiopure TRISPHAT anion (tris(tetrachlorobenzenediolato)phosphate, Figure 1) has been extensively used to induce supramolecular ion-pairing associations with chiral organic, organometallic or coordination cationic compounds. ${ }^{3}$ This $D_{3}$-symmetric anion 25 presents a wide range of extremely interesting properties and for example can act as an efficient NMR chiral shift-reagents for enantiodifferentiation of cations, ${ }^{4}$ as a chiral inducer onto labile cation ${ }^{5}$ and as chiral auxiliary for ion-pair mediated resolution properties by preferential extraction or 30 chromatography.,6 Owning to these very special properties and to the quite easy synthesis and resolution, TRISPHAT anion is now largely disseminate in the scientific community and is becoming a classical resolution auxiliary for many groups around the world. ${ }^{7}$ During the course of our researches 35 aiming at the design of chromophores for nonlinear optical (NLO) applications, we fortunately discovered that, the strong lipophilic character of TRISPHAT anion, already known to deeply modify the chromatographic properties of the associated cation, is also able to greatly enhance its solubility 40 in organic solvents. This particularity is very convenient for the synthesis and purification of polymers or dendrimers ${ }^{8}$ and is a real advantage for the experimental determination of the nonlinear efficiency for which high concentrations are needed. This high solubility requirement is particularly crucial for 45 solution nonlinear transmittance measurements, a third order nonlinear process for which chromophores concentration about 100-300 $\mathrm{g} \mathrm{L}^{-1}$ are commonly used. Such measurements are the key step for the design of optical limiters that are devices able to protect optical sensors like eyes or camera
50 against damages caused by high-energy laser illumination but remaining transparent as long as the light intensity stands below the sensor safety threshold. ${ }^{9}$ In this context, we recently reported the optical limiting behavior of cyanine dyes in the near infra-red around telecommunication wavelength $(1,5$ $\left.{ }_{55} \mu \mathrm{m}\right) .{ }^{10}$ In order to improve the global efficiency of this system, we sought to further increase the solubility of the cationic heptamethine dyes by association with the TRISPHAT anion. In this article, we describe the unexpected formation of a diastereoselective ion-pairing between ${ }_{60}$ heptamethine cyanine and enantiopure TRISPHAT occurring in solid state as well in solution on the basis of X-rays diffraction analysis and NMR spectroscopy.

\section{Results and discussion.}
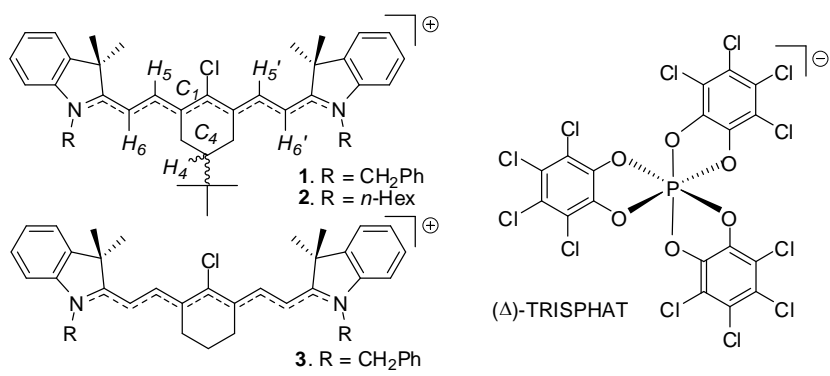

Fig 1. Structure of the studied molecules

Synthesis. The cyanine dyes studied in this article (Figure 1) differs by the functionalisation (or not) of the central cyclohexenyl ring by ${ }^{\mathrm{t}} \mathrm{Bu}$ fragment $[\mathbf{1}][\mathrm{Br}]$, (resp $\left.[\mathbf{3}][\mathrm{Br}]\right)$ and 70 by the distal benzyl or n-hexyl moieties $([\mathbf{1}][\mathrm{Br}]$ and $[2][\mathrm{I}]$ respectively). All these compounds were prepared according to the literature. ${ }^{10,11}$ In all cases, as expected the cationic 
charge is fully delocalized between the two amino donor groups linked by a seven $s p^{2}$ hybridized carbon atoms squeleton. The planarity of the $\pi$-conjugated backbone is ensured by the locked six-member ring and due to the odd 5 number of carbon atoms in the $\pi$-system, all C-C bonds are equivalents, intermediate between simple and double bonds. ${ }^{10,11}$ As a result, the three molecules present a symmetry plane containing the $\mathrm{Cl}, \mathrm{C}_{1}, \mathrm{C}_{4}$ and $\mathrm{H}_{4}$ atoms (Figure 1) and therefore their ${ }^{1} \mathrm{H}$ NMR spectra (Figure $3 \mathrm{a}$ in the case $[\mathbf{1}][\mathrm{Br}]$ ) 10 present a single set of signals for the two vinylic protons $\left(\mathrm{H}_{5} / \mathrm{H}_{5}\right.$, and $\mathrm{H}_{6} / \mathrm{H}_{6}$, Figure 1$)$. It is worth noting that owning to the presence of a symmetry plane, these dyes are not chiral, but the $\mathrm{C}_{4}$ atom in compounds $\mathbf{1}^{+}, \mathbf{2}^{+}$featuring a ${ }^{\mathrm{t}} \mathrm{Bu}$ fragment bears two pro-chiral substituents. Consequently, any breaking 15 of the planar symmetry will lead to the formation of two enantiomers. ${ }^{12}$

Associations of cyanine dyes [1-3][X] (X = Br, I) with $90 \%$ ee [cyn][ $\Delta$-TRISPHAT] $(\text { cyn }=\text { cynchonidinium })^{1,2}$ were carried out by mixing equivalent amounts of both salts in 20 dichloromethane solution at room temperature. The desired [1-3][ $\Delta$-TRISPHAT] were purified by chromatography $\left(\mathrm{SiO}_{2}\right.$, eluent $\mathrm{CH}_{2} \mathrm{Cl}_{2}$ ) as the most eluted compounds. As already observed, replacement of counter-anion by TRISPHAT results in a deep modification of the chromatographic behavior. For 25 instance, in the case of $\mathbf{1}^{+}$, the bromide salt was eluted with a $\mathrm{CH}_{2} \mathrm{Cl}_{2}$-methanol 9/1 mixture. Such modification of chromatographic conditions is classical and can be ascribed to the stronger lipophilic character of TRISPHAT anion. ${ }^{3,13}$ Compounds [1-3][ $\Delta$-TRISPHAT] were characterized by ${ }^{1} \mathrm{H}$ 30 and ${ }^{13} \mathrm{C}$ NMR and gave satisfactorily elemental analysis (see experimental).

Solid state structure. Attempts to crystallize [1][ $\Delta$ TRISPHAT] $(90 \%$ ee) by slow evaporation of methanol35 toluene solution resulted in the formation of single crystal belonging to the centrosymmetric $\mathrm{P}-1$ space group $\left(\mathrm{N}^{\circ} 2\right)$ of the racemate [1][rac-TRISPHAT] containing equal amount of [1][ $\Delta$-TRISPHAT] and [1][ $\Lambda$-TRISPHAT]. Crystal data, refinements parameters and details of the crystallographic 40 packing are reported in the ESI. On the molecular scale (Figure 2 ), the cation $\mathbf{1}^{+}$presents a syn-type arrangement with the two $\mathrm{N}$ atoms on the same side of the methine chain as already observed for other cyanines and a remarkable planarity without any significant twist of the nine $\mathrm{C}\left(s p^{2}\right)$ ${ }_{45}$ carbon skeleton (overall tilt angles is $\left.26^{\circ}\right) .{ }^{14}$ As expected for cyanine-like compounds, the conjugated backbone shows a "polyacetylene-type" stucture with equal C-C bond lengths $(139 \pm 2 \mathrm{pm})$ intermediate between single and double bonds (see table in ESI). This result indicates that the charge is 50 perfectly delocalized between the two distal heterocycles. The planarity is enforced by the fused central cyclohexenyl ring that presents a chair conformation constrained by the thermodynamically favoured equatorial position of the ${ }^{t} \mathrm{Bu}$ fragment. ${ }^{10,14 c}$ This rigid conformation defines two 55 diastereotopic faces according to the position of the out-ofplane $\mathrm{C}_{4}$ atom with respect to the $\pi$-conjugated system (gray plan, Figure 2): The face II contains the $\mathrm{C}_{4}$ carbon and therefore the bulky ${ }^{\mathrm{t}} \mathrm{Bu}$ fragment whereas the opposite face I

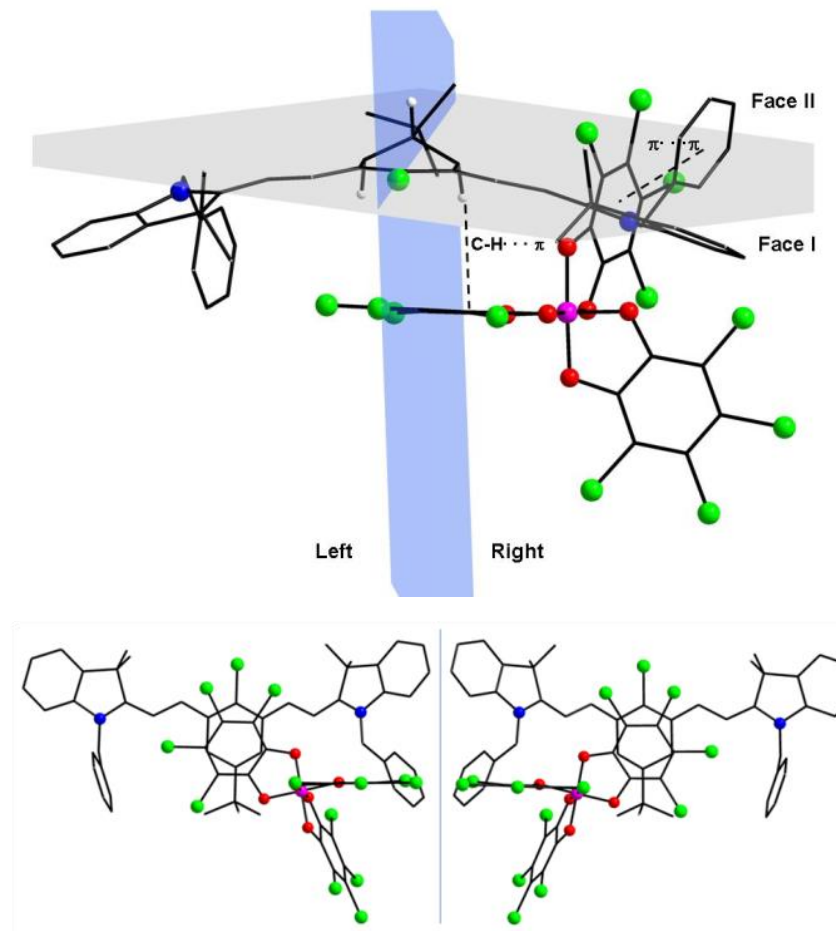

60 Fig 2: X-ray structure of [1][rac-TRISPHAT], $\mathrm{H}$ atoms were omitted for clarity except those involved in supramolecular interactions. (up) representation of the two non-equivalents faces of cyanine cation and supramolecular interaction between $\mathbf{1}^{+}$and $\Delta$-TRISPHAT; (bottom) representation of the two component of the crystal of [1][ $\Delta$-TRISPHAT] 65 (right) and [1][ $\Lambda$-TRISPHAT] (left).

is less sterically hindered. It is woth noting that the bulky TRISPHAT anion is located on this less sterically hindered face I (Figure 2). Furthermore, on this latter face, the presence of the two distal functionalisations on the amino donor groups 70 define two cavities (noted right and left) on both sides of the symmetry plane (blue plane, Figure 2), mirror image one from each other. It is important to remark that $\Delta$-TRISPHAT (resp, $\Lambda$-TRISPHAT) anion interacts selectively with the right (resp, left) side cavity. This selective recognition according to 75 the lock-and-key principle is due to the TRISPHAT helicity. The cohesion of this association is ensured by (i) one $\mathrm{C}-\mathrm{H} \cdots \pi$ interaction $(3.01 \AA)$ between one axial proton of the cyclohexenyl ring and a tetrachlorobenzendiolato ligand and (ii) a $\pi$-stacking interaction $\left(\mathrm{d}_{\pi-\pi} \approx 3.67 \AA\right)$ between the 80 benzyl fragment and a second tetrachlorobenzendiolato ligand (Figure 2, up). ${ }^{15}$ Finally, in the solid state [1][ $\Delta$-(resp- $\Lambda$ TRISPHAT] does not present any symmetry plan and the $\mathrm{C}_{4}$ atom become assymmetric in the global ion-pair. The interaction between $\mathbf{1}^{+}$and $\Delta$-(resp- $\Lambda$ )-TRISPHAT is 85 diastereoselective and results in the formation of a single diasteroisomer in the solid state over the four possible, and furthermore the couple of diastereoisomers [1][ $\Delta$-TRISPHAT] and $[1][\Lambda$-TRISPHAT] are enantiomers one from the other.

${ }_{90}$ Solution NMR studies. The interactions displayed in solution between TRISPHAT and heptamethine dyes were studied by NMR spectroscopy. Initial experiments were carried in an NMR tube in $\mathrm{CDCl}_{3}$ at room temperature between [1][Br] and 
increasing amounts of [cyn][ $\Delta$-TRISPHAT] (90\% ee) (Figure 3 ). The NMR signals of the most easily distinguishable cyanine protons $\mathrm{H}_{5} / \mathrm{H}_{5}$, and $\mathrm{H}_{6} / \mathrm{H}_{6}$, belonging to the conjugated backbone are progressively shifted and splitted, 5 indicating the establishment of a rapid equilibrium between [1][ $\Delta$-TRISPHAT] and [1][Br]. Finally, the ${ }^{1} \mathrm{H}$ NMR spectrum of isolated [1][ $\Delta$-TRISPHAT] (Figure 3e) clearly indicates a splitting of each resonance in two signals of equal intensity. This phenomenon is also observed in the ${ }^{13} \mathrm{C}$ spectra: all the 10 signals split except those of the carbons $\mathrm{C}_{1}$ and $\mathrm{C}_{4}$ belonging to the symmetry plane of the molecule (see Figure $\mathrm{S} 1$ for ${ }^{13} \mathrm{C}$ spectrum). ${ }^{16}$ These observations are in agreement with those observed in the solid state: $\Delta$-TRISPHAT interacts selectively with the right side cavity inducing an asymmetry in the 15 molecule; each vinylic proton $\mathrm{H}_{5} / \mathrm{H}_{5}$, (resp $\mathrm{H}_{6} / \mathrm{H}_{6}$ ) become magnetically non equivalent resulting in the apparition of two signals of equal intensity. The chemical shift difference $\Delta_{55}{ }^{\prime}=$ $\left|\delta\left(\mathrm{H}_{5}\right)-\delta\left(\mathrm{H}_{5},\right)\right|\left(\operatorname{resp}, \Delta_{66}{ }^{\prime}=\left|\delta\left(\mathrm{H}_{6}\right)-\delta\left(\mathrm{H}_{6}{ }^{\prime}\right)\right|\right)$ of 0.03 and 0.06 ppm in chloroform- $d_{l}$ allows to quantify the strength of the 20 supramolecular interaction. Furthermore interestingly, the magnitude of these chemical shift differentiation strongly increases in non-dissociating solvents and higher values were measured in benzene- $d_{6}, \Delta_{55^{\prime}}=0.09 \mathrm{ppm}, \Delta_{66}{ }^{\prime}=0.29 \mathrm{ppm}$ (Figure 4c). On the contrary, the splitting completely ${ }_{25}$ disappears in highly dissociating polar solvent like DMSO-d (Figure S2). Such solvent effects have been frequently described in the literature for other systems and are the clear signature of a supramolecular ion-pairing effect in solution. ${ }^{4,17}$

In addition, ${ }^{1} \mathrm{H}$ NMR spectra of [1][ $\Lambda$-TRISPHAT] $(86 \%$ 30 ee) and [1][rac-TRISPHAT] have also been recorded (Figure S3). Association with $\Lambda$-TRISPHAT results in a very similar splitting of the signals than that observed for $\Delta$-TRISPHAT. ${ }^{15}$ On the other hand, the ${ }^{1} \mathrm{H}$ NMR (and ${ }^{13} \mathrm{C}$ NMR) spectrum of [1][rac-TRISPHAT] shows only one set of signal like in the 35 case of $[\mathbf{1}][\mathrm{Br}]$, a result that can be again explained the rapid equilibrium between [1][ $\Delta$-TRISPHAT $]$ and $[[1][\Lambda$ TRISPHAT] resulting in averaged NMR chemical shift.

In order to get more insight into this supramolecular ionpairing effect, the influence of the substituents of $\mathbf{1}^{+}$on the 40 association with $\Delta$-TRISPHAT has been examined. Heptamethine dye $\mathbf{2}^{+}$, featuring $n$-hexyl pendant groups instead of benzyl ones also present a splitting of the ${ }^{1} \mathrm{H}$ NMR signals when associating with $\Delta$-TRISPHAT as shown Figure $4 \mathrm{~b}$. However, the differentiation is less pronounced than for $\mathbf{1}^{+}$ ${ }_{45}\left(\Delta_{55}{ }^{\prime}=0.03 \mathrm{ppm}, \Delta_{66}{ }^{\prime}=0.13 \mathrm{ppm}\right.$ in benzene- $\left.d_{6}\right)$ and almost not observable in $\mathrm{CDCl}_{3}$. In that case, the supramolecular association is weaker, underlining the role of the benzyl moieties in the recognition process, as already observed in the solid state (Figure 2). Finally, the role of the ${ }^{t} \mathrm{Bu}$ fragment at 50 the $C_{4}$ position as been examined. Ion-pairing formation also occurs between $\Delta$-TRISPHAT and dye $\mathbf{3}^{+}$, containing benzyl groups but no more ${ }^{t} \mathrm{Bu}$ fragment (Figure 1) as evidenced by thin-layer chromatography. But, by NMR, no more signals splitting is observed even in non-dissociating solvents (Figure ${ }_{55} 4 \mathrm{a}$ ). This result was expected since in $\mathbf{3}^{+}$, the $\mathrm{C}_{4}$ atom is substituted by two pairs of homotopic substituent; hence, $\mathbf{3}^{+}$ presents two equivalents faces with a rapid conformation equilibrium and there is no possibility for the TRISPHAT to discriminate between them. These experiments emphasis the 60 crucial role played by the ${ }^{t} \mathrm{Bu}$ fragment in $\mathbf{1}^{+}$or $\mathbf{2}^{+}$because it fixes the conformation of the central cyclohexenyl ring allowing the differentiation between the two faces of the molecule, and the additional role of the benzyl groups who reinforces the supramolecular interaction. 65

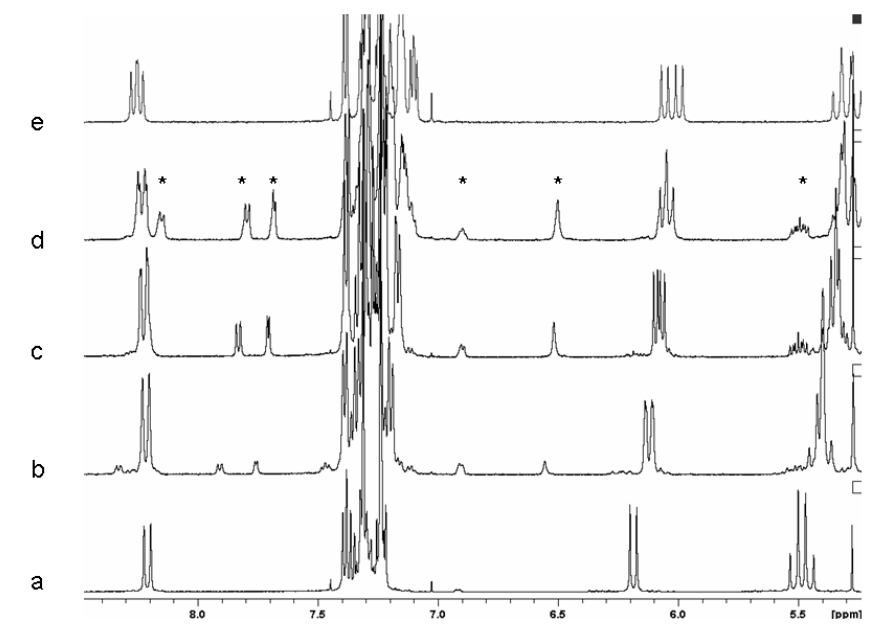

Fig. 3. Aromatic region of ${ }^{1} \mathrm{H}$ NMR $\left(\mathrm{CDCl}_{3}\right.$, TA, $\left.500 \mathrm{MHz}\right)$ of $[\mathbf{1}][\mathrm{Br}]$ with increasing quantities of [cyn][ $\Delta$-TRISPHAT] a: 0 eq., $\mathrm{b}: 0.25$ eq., $\mathrm{c}$ : 0.5 eq., $d: 0.75$ eq. e : 1 eq. (*, NMR signal of cyn).

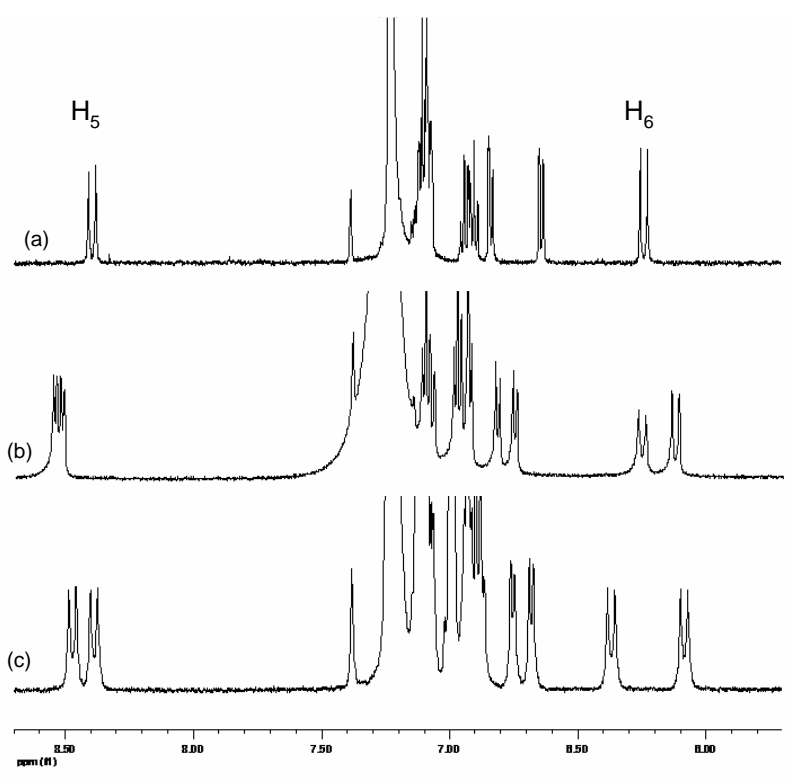

70 Fig. 4. Aromatic region of ${ }^{1} \mathrm{H}$ NMR spectra (benzene- $d_{6}$, RT, $500 \mathrm{MHz}$ ) of (a) [3][ $\Delta$-TRISPHAT], (b) [2][ $\Delta$-TRISPHAT] and (c) [1][ $\Delta$ TRISPHAT].

\section{Concluding remarks.}

We present in this paper a novel case of association using 75 enantiopure TRISPHAT. Contrary to previous cases in which shorter monomethine dyes presented an helicoidal axis of chirality, ${ }^{13 a, 18,19}$ the studied heptamethine dyes $\mathbf{1}^{+}, \mathbf{2}^{+}$and $\mathbf{3}^{+}$ featuring a fused cyclohexenyl ring does not present any chirality element due to the longer distances between the 
terminal indolenine groups. However, in the case of $\mathbf{1}^{+}$and $\mathbf{2}^{+}$ the conformation of the cyclohexenyl moieties is constrained by the thermodynamically favoured equatorial position of the ter-butyl fragment. As a consequence, the faces of the 5 molecules become diastereotopic. The X-ray structure indicates that, $\Delta^{-}$(resp. $\Lambda^{-}$) TRISPHAT interacts preferentially in the solid state with the right (resp. left) cavity defined by the cyclohexenyl ring and the distal benzyl substituant (Figure 1). This diastereoselective shape 10 interaction breaks the planar symmetry of the supramolecule and the $\mathrm{C}_{4}$ atom is now asymmetric resulting in the formation of a single diastereoisomer. Importantly, an identical diastereoselective ion-pairing interaction is observed in solution in non-dissociating solvents inducing an asymmetry 15 of the molecule as illustrated by the splitting of the NMR signals. It is worth noting that the interaction between $\mathbf{1}^{+}$and enantiopure TRISPHAT leads to the formation of a single diastereoisomer over the four possible clearly underlining the high selectivity of the supramolecular interaction. Finally, the 20 nature of the distal substituents (benzyl vs n-hexyl) defining the two cavities control the strength of this interaction: the more rigid benzyl fragment, allowing additional $\pi-\pi$ stacking interactions with TRISPHAT induces the strongest interaction. These results contribute to expand the utilization 25 scope of TRISPHAT ion: it is able to induce strong ionpairing effect with non chiral molecule and to "reveal" the chirality of a pro-chiral compound.

Acknowledgement. The authors thank the Direction Générale de l'armement (DGA) for a grant to PAB.

\section{${ }_{30}$ Experimental section.}

All reactions were routinely performed under argon. NMR spectra were recorded at room temperature on a BRUKER AC 500 operating at $499.84 \mathrm{MHz}$ for ${ }^{1} \mathrm{H}$ NMR and on a BRUKER AC 200 operating at $125.8 \mathrm{MHz}$ and for ${ }^{13} \mathrm{C}$ and 81.91 for ${ }^{31} \mathrm{P}$ 35 respectively . Data are listed in parts per million (ppm). UVvisible spectra were recorded on a Jasco V-550 spectrophotometer in diluted dichloromethane (resp. toluene) solution ( $c a \cdot 10^{-5}$ mol. $\mathrm{L}^{-1}$ ). Elemental analysis were performed by the Service Central d'Analyse du CNRS (Vernaison, 40 France). Column Chromatography was performed on Merck Gerduran $60(40-63 \mu \mathrm{m})$ silica using dichloromethane as eluent.

\section{General Procedure for anion substitution:}

[1-3][Br] (1 eq.) was dissolved in DCM $(25 \mathrm{~mL})$. 45 [cyn][TRISPHAT] (1 eq.) was added and the solution was stirred $30 \mathrm{mn}$ at room temperature. The solution was washed with water $(3 \times 15 \mathrm{~mL})$, filtrated trough a silica plug (washed with DCM), and dried over $\mathrm{Na}_{2} \mathrm{SO}_{4}$. Then the solvents were evaporated to afford a green solid.

${ }_{50}$ [1][D-TRISPHAT]. yield 85\%; ${ }^{1} \mathrm{H}$ NMR (499.84 MHz, $\left.\mathrm{CDCl}_{3}\right): \delta 0.85(\mathrm{~s}, 9 \mathrm{H}), 1.31(\mathrm{~m}, 1 \mathrm{H}), 1.72(\mathrm{~s}, 6 \mathrm{H}), 1.73(\mathrm{~s}$, $3 \mathrm{H}) 1.74(\mathrm{~s}, 3 \mathrm{H}), 1.80\left(\mathrm{dd},{ }^{3} J=10 \mathrm{~Hz},{ }^{2} J=10 \mathrm{~Hz}, 1 \mathrm{H}\right), 1.85$ $\left(\mathrm{dd},{ }^{3} J=10 \mathrm{~Hz},{ }^{2} J=10 \mathrm{~Hz}, 1 \mathrm{H}\right), 2.50(\mathrm{~m}, 2 \mathrm{H}), 5.16\left(\mathrm{~d},{ }^{2} J=\right.$ $17 \mathrm{~Hz}, 1 \mathrm{H}), 5.26\left(\mathrm{~d},{ }^{2} J=17 \mathrm{~Hz}, 1 \mathrm{H}\right), 5.30\left(\mathrm{~d},{ }^{2} J=17 \mathrm{~Hz}, 1 \mathrm{H}\right)$, ${ }_{55} 5.36\left(\mathrm{~d},{ }^{2} J=17 \mathrm{~Hz}, 1 \mathrm{H}\right), 5.99\left(\mathrm{~d},{ }^{3} J=15 \mathrm{~Hz}, 1 \mathrm{H}\right), 6.05\left(\mathrm{~d},{ }^{3} J\right.$
$=15 \mathrm{~Hz}, 1 \mathrm{H}), 7.1-7.5(\mathrm{~m}, 18 \mathrm{H}), 8.24\left(\mathrm{~d},{ }^{3} J=15 \mathrm{~Hz}, 1 \mathrm{H}\right), 8.26$ $\left(\mathrm{d},{ }^{3} \mathrm{~J}=15 \mathrm{~Hz}, 1 \mathrm{H}\right) .{ }^{13} \mathrm{C} \mathrm{NMR}\left(50.32 \mathrm{MHz}, \mathrm{CDCl}_{3}\right): 27.5$, 27.6, 28.5, 28.6, 32.5, 42.1, 48.5, 48.6, 49.7, 49.8, 102.0, $102.1,111.0,111.3,114.1,114.2,122.7,125.9,126.0,126.5$, ${ }_{60} 126.6,128.3,128.4,128.7,128.8,129.2,129.7,134.1,141.0$, $142.3,142.7,142.8,145.1,145.3,151.7,173.0,173.3 .{ }^{31} \mathrm{P}$ NMR (91 $\left.\mathrm{MHz}, \mathrm{CDCl}_{3}\right): \delta-80.7$. Anal. calcd. for $\mathrm{C}_{66} \mathrm{H}_{60} \mathrm{~N}_{2} \mathrm{O}_{10} \mathrm{PCl}_{13}$ : C, 51.71, H, 3.94, N, 1.83, Found C, 51.74, $\mathrm{H}, 3.52, \mathrm{~N}, 1.71$. UV-Vis $\left(\mathrm{CH}_{2} \mathrm{Cl}_{2}\right): \lambda_{\max }=791 \mathrm{~nm}\left(\varepsilon_{\max }=\right.$ 65320000 L.mol $\left.{ }^{-1} \cdot \mathrm{cm}^{-1}\right)$.

[1][ $\Lambda$-TRISPHAT]. ${ }^{1} \mathrm{H}$ NMR (499.84 $\left.\mathrm{MHz}, \mathrm{CDCl}_{3}\right): \delta 0.85$ (s, 9H), $1.31(\mathrm{~m}, 1 \mathrm{H}), 1.72(\mathrm{~s}, 6 \mathrm{H}), 1.73(\mathrm{~s}, 3 \mathrm{H}) 1.74(\mathrm{~s}, 3 \mathrm{H})$, $1.80\left(\mathrm{dd},{ }^{3} \mathrm{~J}=10 \mathrm{~Hz},{ }^{2} \mathrm{~J}=10 \mathrm{~Hz}, 1 \mathrm{H}\right), 1.85\left(\mathrm{dd},{ }^{3} \mathrm{~J}=10 \mathrm{~Hz},{ }^{2} J\right.$ $=10 \mathrm{~Hz}, 1 \mathrm{H}), 2.49(\mathrm{~m}, 2 \mathrm{H}), 5.16\left(\mathrm{~d},{ }^{2} J=17 \mathrm{~Hz}, 1 \mathrm{H}\right), 5.26(\mathrm{~d}$, $\left.{ }_{70}^{2} J=17 \mathrm{~Hz}, 1 \mathrm{H}\right), 5.30\left(\mathrm{~d},{ }^{2} J=17 \mathrm{~Hz}, 1 \mathrm{H}\right), 5.36\left(\mathrm{~d},{ }^{2} J=17 \mathrm{~Hz}\right.$, $1 \mathrm{H}), 6.00\left(\mathrm{~d},{ }^{3} \mathrm{~J}=15 \mathrm{~Hz}, 1 \mathrm{H}\right), 6.03\left(\mathrm{~d},{ }^{3} \mathrm{~J}=15 \mathrm{~Hz}, 1 \mathrm{H}\right), 7.1-$ $7.5(\mathrm{~m}, 18 \mathrm{H}), 8.24\left(\mathrm{~d},{ }^{3} \mathrm{~J}=15 \mathrm{~Hz}, 1 \mathrm{H}\right), 8.26\left(\mathrm{~d},{ }^{3} J=15 \mathrm{~Hz}\right.$, $1 \mathrm{H})$.

[1][rac -TRISPHAT]. ${ }^{1} \mathrm{H}$ NMR $\left(200.13 \mathrm{MHz}, \mathrm{CDCl}_{3}\right): \delta 0.84$ $75(\mathrm{~s}, 9 \mathrm{H}), 1.30(\mathrm{~m}, 1 \mathrm{H}), 1.71(\mathrm{~s}, 6 \mathrm{H}), 1.73(\mathrm{~s}, 6 \mathrm{H}), 1.86\left(\mathrm{dd},{ }^{3} \mathrm{~J}=\right.$ $\left.13 \mathrm{~Hz},{ }^{2} J=13 \mathrm{~Hz}, 2 \mathrm{H}\right), 2.50\left(\mathrm{dd},{ }^{3} J=2 \mathrm{~Hz},{ }^{2} J=13 \mathrm{~Hz}, 2 \mathrm{H}\right)$, $5.23\left(\mathrm{~d},{ }^{2} J=16 \mathrm{~Hz}, 2 \mathrm{H}\right), 5.29\left(\mathrm{~d},{ }^{2} J=16 \mathrm{~Hz}, 2 \mathrm{H}\right), 6.01\left(\mathrm{~d},{ }^{3} J\right.$ $=14 \mathrm{~Hz}, 2 \mathrm{H}), 7.2-7.5(\mathrm{~m}, 18 \mathrm{H}), 8.25\left(\mathrm{~d},{ }^{3} \mathrm{~J}=14 \mathrm{~Hz}, 2 \mathrm{H}\right) \cdot{ }^{13} \mathrm{C}$ NMR (50.32 MHz, $\left.\mathrm{CDCl}_{3}\right): \delta$ 27.4, 28.5, 28.6, 32.4, 42.1, ${ }_{80} 48.6,49.7,102.0,111.2,114.1,122.6,122.7,125.9,126.5$, $128.4,128.8,129.3,129.7,134.1,141.0,142.2,142.8,145.2$, $151.6,173.1$.

[2][D-TRISPHAT]. yield $=80 \% ;{ }^{1} \mathrm{H}$ NMR $(499.84 \mathrm{MHz}$, $\left.\mathrm{CDCl}_{3}\right): \delta 0.85\left(\mathrm{t},{ }^{3} \mathrm{~J}=8 \mathrm{~Hz}, 6 \mathrm{H}\right), 1.03(\mathrm{~s}, 9 \mathrm{H}), 1.30-1.60(\mathrm{~m}$, $\left.{ }_{85} 18 \mathrm{H}\right), 1.70(\mathrm{~s}, 12 \mathrm{H}), 1.80-1.90(\mathrm{~m}, 4 \mathrm{H}), 2.1-2.3(\mathrm{~m}, 2 \mathrm{H}), 2.80$ $\left(\mathrm{dd},{ }^{3} J=2 \mathrm{~Hz},{ }^{2} J=10 \mathrm{~Hz}, 2 \mathrm{H}\right), 3.9-4.1(\mathrm{~m}, 2 \mathrm{H}), 6.05(\mathrm{~m}$, $2 \mathrm{H}), 7.09\left(\mathrm{~d},{ }^{3} \mathrm{~J}=8 \mathrm{~Hz}, 2 \mathrm{H}\right) 7.3-7.4(\mathrm{~m}, 6 \mathrm{H}), 8.35\left(\mathrm{~d},{ }^{3} J=15\right.$ $\mathrm{Hz}, 2 \mathrm{H}) .{ }^{31} \mathrm{P} \mathrm{NMR}\left(91 \mathrm{MHz}, \mathrm{CDCl}_{3}\right): \delta-80.9$. Anal. calcd for $\mathrm{C}_{64} \mathrm{H}_{50} \mathrm{~N}_{2}{ }_{9} \mathrm{PCl}_{13}$ : C, 52.40, H, 4.53, N, 1.91, Found C, 52.27, ${ }_{90} \mathrm{H}, 4.39$, N, 1.78. UV-Vis $\left(\mathrm{CH}_{2} \mathrm{Cl}_{2}\right): \lambda_{\max }=786 \mathrm{~nm}\left(\varepsilon_{\max }=\right.$ 290000 L. $\left.\mathrm{mol}^{-1} \cdot \mathrm{cm}^{-1}\right)$.

[3][D-TRISPHAT]. yield $=80 \% ;{ }^{1} \mathrm{H}$ NMR $(499.84 \mathrm{MHz}$, $\left.\mathrm{CDCl}_{3}\right): \delta 1.61(\mathrm{~m}, 2 \mathrm{H}), 1.75(\mathrm{~s}, 12 \mathrm{H}), 2.2-2.4(\mathrm{~m}, 4 \mathrm{H}), 5.20$ $\left(\mathrm{d},{ }^{2} J=17 \mathrm{~Hz}, 2 \mathrm{H}\right), 5.31\left(\mathrm{~d},{ }^{2} J=17 \mathrm{~Hz}, 2 \mathrm{H}\right), 6.07\left(\mathrm{~d},{ }^{3} J=15\right.$ $\left.{ }_{95} \mathrm{~Hz}, 2 \mathrm{H}\right), 7.04\left(\mathrm{~d},{ }^{3} \mathrm{~J}=8 \mathrm{~Hz}, 2 \mathrm{H}\right), 7.1-7.3(\mathrm{~m}, 16 \mathrm{H}), 7.38\left(\mathrm{~d},{ }^{3} J\right.$ $=8 \mathrm{~Hz}, 2 \mathrm{H}), 8.29\left(\mathrm{~d},{ }^{3} \mathrm{~J}=15 \mathrm{~Hz}, 2 \mathrm{H}\right) .{ }^{31} \mathrm{P} \mathrm{NMR}(91 \mathrm{MHz}$, $\left.\mathrm{CDCl}_{3}\right): \delta$-80.7. Anal. calcd for $\mathrm{C}_{62} \mathrm{H}_{48} \mathrm{~N}_{2} \mathrm{O}_{8} \mathrm{PCl}_{13}$ : C, 51.68, $\mathrm{H}, 3.36, \mathrm{~N}, 1.94$, Found C, 51.97, H, 3.42, N, 1.77. UV-Vis $\left(\mathrm{CH}_{2} \mathrm{Cl}_{2}\right): \lambda_{\max }=794 \mathrm{~nm}\left(\varepsilon_{\max }=290000 \mathrm{~L} \cdot \mathrm{mol}^{-1} \cdot \mathrm{cm}^{-1}\right)$.

\section{${ }_{100}$ Notes and references}

a University of Lyon, ICL, CNRS - Ecole Normale Supérieure de Lyon, Laboratoire de Chimie, UMR 5182, 46 allée d'Italie, 69007 Lyon, France. olivier.maury@ens-lyon.fr.

Electronic Supplementary Information (ESI) available: cif file for compound [1][rac-TRISPHAT], CCDC 717753; supplementary crystallographic information and crystal packing description, additionnal NMR spectra (Figure S1, S2 and S3).

1 J. Lacour, C. Ginglinger, C. Grivet, G. Bernardinelli, Angew. Chem. Int. Ed., 1997, 36, 608-610.

2 F. Faverger, C. Goujon-Ginglinger D. Monchaud, J. Lacour, J. Org. Chem., 2004, 69, 8521-8524. 
3 For reviews, see: a) J. Lacour, R. Franz, Org. Biomol. Chem., 2005, 3, 15-19; b) J. Lacour, V. Hebbe-Viton, Chem. Soc. Rev., 2003, 32, $373-$ 382.

4 a) J. Lacour, C. Ginglinger, F. Faverger, S. Torche-Haldimann, Chem. Commun., 1997, 2285-2286; b) O. Maury, J. Lacour, H. Le Bozec, Eur. J. Inorg. Chem. 2001, 201-204; c) R. Franz, C.S. Grange, N.K. Al-Rasbi, M. D. Ward, J. Lacour, Chem. Commun., 2007, 1459-1461. 5 J. J. Jodry, R. Frantz, J. Lacour Inorg. Chem. 2004, 43, 3329-3331.

6 J. Lacour, S. Torche-Haldimann, J.J. Jodry, C. Ginglinger, F. Faverger, Chem. Commun., 1998, 1733-1734; b) J.J. Jodry, J. Lacour, Chem. Eur. J. 2000, 6, 4297-4304

7 For selected recent examples, see: a) C. R. Brodie, J. R. Aldrich-Wright, Eur. J. Inorg. Chem. 2007, 4781-4793; b) O. Hamelin, J. Pécaut, M. Fontecave, Chem. Eur. J., 2004, 10, 2548-2554; c) A. Auffrant, A. Barbieri, F. Barigelletti, J. Lacour, P. Mobian, J.-P. Collin, J.-P. Sauvage, B. Ventura; Inorg. Chem. 2007, 46, 6911-6919; d) L. Mimassi, C. Guyard-Duhayon, M. N. Rager, H. Amouri, Inorg. Chem. 2004, 43, 6644-6649 ; e) B. W. Laursen, S. Nygaard, J. O. Jeppesen, J.F. Stoddart, Org. Lett. 2004, 6, 4167-4170.

8 a) T. Le Bouder; O. Maury, H. Le Bozec; I. Ledoux, J. Zyss Chem. Commun., 2001, 2430-2431; b) T. Le Bouder, O. Maury, A. Bondon, K. Costuas, E. Amouyal, I. Ledoux, J. Zyss, H.Le Bozec J. Am. Chem. Soc. 2003, 125, 12884-12899; c) L. Viau, S. Bidault, O. Maury, S. Brasselet, I. Ledoux, J. Zyss, E. Ishow, K. Nakatani, H. Le Bozec J. Am. Chem. Soc. 2004, 124, 8386-8387.

9 For a review see: C.W. Spangler, J. Mater. Chem., 1999, 9, 2013-2020 and references therein.

10 a) P. A. Bouit, G. Wetzel, G. Berginc, L. Toupet, P. Feneyrou, Y. Bretonnière, O. Maury, C. Andraud, Chem. Mater. 2007, 19, 53255335 ; b) P. A. Bouit, R. Westlund, P. Feneyrou, O. Maury, M. Malkoch, E. Malmström, C. Andraud, New J. Chem., 2009 in press.

11 X. Chen, X. Peng, A. Cui, B. Wang, L. Wang, R. Zhang, J. Photochem. Photobiol. A: Chem., 2006, 181, 79-85.

12 Related neutral push-pull chromophores featuring no planar symmetry are present under two enantiomeric forms as illustrated by X-rays diffraction analysis (ref. 10) and chiral HPLC. (P.A. Bouit, PhD thesis, 2008).

13 a) J. Lacour, S. Barchéchath, J. J. Jodry, C. Ginglinger, Tetrahedron Lett., 1998, 567-570; b) C. Pérollier, G. Bernardinelli, J. Lacour, Chirality, 2007, 20, 313-324.

14 a) Y. Nagao, T. Sakai, K. Kozawa, T. Urano, Dyes Pigm .2007, 73, 344-352. b) Dai, Z.F.; B. X. Peng, X. A. Chen, Dyes Pigm. 1999, 40, 219-223. c) P.-A. Bouit, E. Di Piazza, S. Rigaut, B. Le Guennic, C. Aronica, L. Toupet, C. Andraud, O. Maury, Org. Lett. 2008, 10, 4159-4162.

15 a) C. Janiak J. Chem. Soc. Dalton Trans, 2000, 3885-.896; b) M. Nishio CrystEngComm, 2004, 6, 130-158.

16 Similar behaviour has already been observed in the case of the association of racemic or enantiopure TRISPHAT with $C s$-symmetric palladium complexes, see: D. Zalubovskis, A. Bouet, E. Fjellander, S. Constant, D. Linder, A. Fischer, J. Lacour, T. Privalov, C. Moberg, J. Am. Chem. Soc., 2008, 130, 1845-1855.

17 J. G. Planas, D. Prim, E. Rose, F. Rose-Munch, D. Monchaud, J. Lacour Organometallics 2001, 20, 4107-4110.

18 J. Lacour, A. Londez, C. Goujon-Ginglinger, V. Buss, G. Bernardinelli, Org. Lett., 2000, 2, 4185-4188.

19 For supramolecular interaction between cyanines and other chiral anions see: a) D. J. Owen, G. B. Schuster, J. Am. Chem . Soc. 1996, 188, 259-256. b) D. J. Owen, D. Vanderveer, G. B. Schuster, J. Am. Chem. Soc. 1998, 120, 1705-1717. 